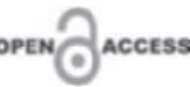

ARTIGO ORIGINAL

\title{
The Use of Pedometer as a Stimulus to the Physical Activity in the Hypertensive Patients with Difficult-to- Control Hypertension: A Controlled Randomized Study
}

\author{
O Uso do Pedômetro como Estímulo à Atividade Física em \\ Hipertensos de Dificil Controle da Hipertensão: \\ Um Estudo Randomizado Controlado
}

Isabela Pilar Moraes Alves de Souza ${ }^{1}{ }^{1}$ Jamerson Sampaio $^{1}$, Mariana LesquivesVieira ${ }^{2}$, Patrícia Alcântara Viana ${ }^{2}$, Gustavo Freitas Feitosa ${ }^{1}$, Gilson Soares Feitosa ${ }^{1,2}$

${ }^{1}$ Serviço de Cardiologia do Hospital Santa Izabel da Santa Casa de Misericórdia da Bahia; ${ }^{2}$ Núcleo de Pesquisa do Hospital Santa Izabel; Salvador, Bahia, Brazil

Correspondence addresses:

Gilson Feitosa, MD

Email: gfeitosa@cardiol.br

Received: October 29, 2018

Revised: December 15, 2018

Accepted: January 28, 2019

Published: March 27, 2019

Data Availability Statement: All relevant data are within the paper and its Supporting Information files.

Funding: This work was the result of authors' initiative. There was no support of research or publication funds.

Competing interests: The authors have declared that no competing interests exist.

Copyright

C 2019 by Santa Casa de Misericórdia da Bahia.

All rights reserved.

ISSN: 2526-5563
Regular physical activity contributes to better control of hypertension in addition to other dietary measures and medications. The practice of physical activity and long term adherence to it is not consistently observed in a hypertensive population. We evaluated the possible role of the use of a pedometer as a stimulus to enhance the physical activity in a selected hypertensive population. We performed a prospective, randomized trial in a difficult-to-control hypertensive population that had been followed in the hypertensive clinic of the Hospital Santa Izabel of Santa Casa de Misericórdia da Bahia. This study compared two groups: Pedometer Group, which uses a pocket digital pedometer (Omron HJ-321) in addition to the usual medical recommendation; and Control Group, which was submitted to the regular medical recommendation without a pedometer. The performance was analyzed by the number of steps during 12 weeks observation period with the primary endpoint at first week. Forty-two patients were studied. Patients had largely low-income and low-education characteristics. Their initial number of steps at week 1 were: 6,191.7 (667.3), and 5,249.1 (549.5) for the Control and Pedometer Groups $(p=0.28)$, respectively. At the end of a 12-week observation, the results were: $6,097.6(547.0)$, and $5,913.0(730.6)(p=0.84)$ for the Control and Pedometer Groups, respectively. In a population of difficult-to-control hypertension, which already had a relatively high number of steps to perform its regular activities of day-life at the beginning of the study, the use of a pedometer does not seem to enhance the level of physical activity beyond what is accomplished by the structured information that is provided in the hypertension clinic.

Keywords: Hypertension; Pedometer; Exercise, Physical.

\section{Introduction}

Physical activity has been associated with improvement in prevention and prognosis in conditions, such as coronary artery disease and cerebral vascular, diabetes, osteoporosis and depression, and other conditions. ${ }^{1}$

Walking 120 minutes or more per week results in a relative reduction in mortality of $39 \%$ in 12 years in a diabetic population, or, there could be prevention of 1 death a year for 61 patients who decide to exercise. ${ }^{2}$ 
Moreover, controlled clinical studies demonstrate that physical activity promotes the reduction of blood pressure and can be an important adjuvant in the prevention and treatment of hypertension. ${ }^{3,4}$

Thus, several guidelines have recommended 30 minutes, 5 times a week, of moderate physical activity, in a continuous or intercalated fashion, as long as the physical condition allows.

Some studies suggest that the use of a pedometer use could help in stimulating the exercise practice..$^{5-7}$ Despite the evidence demonstrated within clinical trials, the adherence to hygienic -dietetic measures, such as dietary and exercise and behavioral attitudes, in the long term follow-up, is less than the desirable..$^{8,9}$

Promoting long term adherence is, therefore, a goal to be attended.

The educational level seems to be an important contributor to the adherence to physical activities, and the less educated population has been less prone to adhesion to preventive measures.

We, therefore, directed our attention to a population of a lesser degree of financial resources and education.

So, the aim of our study was to evaluate whether the adoption of a pedometer, which allows steps counting, could be a tool in order to motivate the adherence to practicing exercise in a population of hypertensives of difficult control and poor education.

\section{Material and Methods}

This was a prospective, parallel group-control, randomized study, in which we evaluated the effect of the use of a pedometer for 12 weeks.

The study population was the difficult-to-control hypertensive patients defined as having a regular utilization of two antihypertensive agents for at least a month and maintaining a blood pressure equal or above $140 / 90 \mathrm{mmHg}$, or obtaining blood pressure control with the utilization of three or more antihypertensive agents and who were been followed in our hypertension outpatient clinic in Hospital Santa Izabel of Santa Casa de Misericórdia da Bahia in Salvador, Bahia, Brazil.

Inclusion and exclusion criteria to the population studied are described in Tables 1 and 2, respectively.
Table 1. Inclusion criteria.

Hypertension of difficult control;

Age between 18 and 80 years;

Capable of performing an exercise test negative for ischemia or arrhythmias;

Able to understand instructions;

Approved consent form.

Table 2. Exclusion criteria.

Engaged in programmed physical activity of greater than walking 150 minutes a week;

NYHA class iii-IV;

Osteoarthritis with difficult for walking;

Active malignant neoplasia;

Significant depression or psychiatric disturbance;

Pregnancy;

Complex ventricular arrhythmias or high degree atrioventricular block;

Significant valve heart disease;

History of coronary artery disease;

Intermittent claudicating;

BP greater than $180 \mathrm{mmHg}$ for systolic or $110 \mathrm{mmHg}$ for diastolic.

We sought to engage patients who were able to follow a formal program of exercise and avoided those who presented difficulties to perform the activities or might have risk involved.

The blood pressure was measured with an automated calibrated digital sphygmomanometer according to standard recommendations by the Brazilian Society of Cardiology Guideline for Hypertension. ${ }^{10}$

In the first visit (screening), patients did an exercise test and the ones with ischemia were excluded.

In the second visit (week 2), laboratory test and a measurement of the sympathetic activity by means of a digital electrocardiograph (Wincardio 6.1.1.36 from Micromed) with a 20 minutes basic recording and further spectral analysis of the heart rate variability were performed.

In this visit, a pocket digital pedometer (Omron HJ-321) (Figure 1), calibrated for the patient's height and weight, was given to all patients, blinded and 
randomized, using a covering display by an adhesive tape, which avoided the patients of counting the number of steps. Careful instruction was given for them about the use of the pedometer for the next 7 consecutive days.

Figure 1. Pedometer Omron ${ }^{\mathrm{TM}} \mathrm{HJ}-321$.



In the third visit, (week 3), the pedometers were returned, and a general health education instruction was given to all patients, including an incentive to an enhancement in physical practice and a DASH (Dietary Approaches to Stop Hypertension) $\operatorname{diet}^{11,12}$.

Patients were then randomized to Pedometer Group, which received the pedometer without the adhesive tape and advised about its use and daily steps counting; and to Control Group, which not received the pedometer, and followed the general instruction already given and standard treatment.

In the visit 4 (week 4), patients were re-evaluated by the medical personnel without the knowledge of the pedometer results.

In the visit 5 (week 11), the Control Group received the blinded pedometer.

In the visit 6 (week 12), there was a final evaluation and the pedometer data was analyzed for both Groups.

Demographic characteristics were evaluated. The race was accepted as a self-description as white, mulatto, and black. The level of education was estimated according to the degree of education and was considered elementary (complete or incomplete), high-school, and college degree levels.

The income was considered as a multiple of the minimum wage earned by the subjects.

Anthropometric measurements such as weight in kilograms was done in a standard digital scale; the height was measured in meters without the shoes, body mass index was the result of weight in kilograms divided by height in square meters, and abdominal circumference was measured in centimeters in the middle of the distance between the lower rib and the iliac crest.

Laboratory tests were performed in the standard way.

Diabetes and dyslipidemia were registered by history or blood exams.

The pedometer data were analyzed regarding the number of daily steps.

The step size was individualized for each patient as the result of the average of 10 steps done in a regular horizontal surface.

An additional measurement was the number of aerobic steps considered the number of steps during a walk that lasted more than 10 uninterrupted minutes. The distance was the measured distance walked during the use of the pedometer.

The classes of antihypertensive medications were counted in the beginning and at the end of the study.

The primary outcome was the change in the number of daily steps in 12 weeks and secondary endpoints were aerobic steps, changes in blood pressure, heart rate, weight, abdominal circumference, and number of medicines.

\section{Sample size}

According to previous studies done with diabetics, in which the average number of steps was 4,094 steps and a standard deviation of $2,285,{ }^{13}$ and considering an effect of an increment of steps of $30 \%$, in order to obtain a statistical power of 0.80 with an admissible alpha error of less than 0.05 , we planned to include 110 patients. We pre-determined an interim analysis with the inclusion of approximately half of this total patient and if the effect was of $50 \%$ we only needed to include 42 patients to keep the 0.80 statistical power.

The analysis was done with 42 patients, which indicated no significant difference between the Groups regarding the primary endpoint. So, it was decided to stop the inclusion of patients in the study for the unlikelihood of showing a difference with the continuation of the study.

The statistical analysis was done by the Statistical Program Stata 14.2. The comparison was done by 
Student's T-test, otherwise by the Mann-Whitney, considering the normal distribution for the continuous variables. Categorical variables were evaluated by the Chi-square or Fischer exact tests.

All patients were instructed about the study and gave a signed consent form.

The study was approved by the local ethical committee (Santa Casa de Misericórdia da Bahia Number 856.746).

\section{Results}

From September, 2014, through February, 2017, 400 patients were examined in the outpatient department of hypertension, and 100 were considered for participating in the study.

Table 3. Clinical and demographic baseline findings.
Forty-two patients underwent a provocative test for ischemia; 37 had a negative ECG stress test, and despite 5 had a positive ECG stress test with a negative nuclear SPECT test, they were included in the study. Baseline demographic and clinical characteristics are described in Table 3.

Patients were middle-aged, predominantly female and black. Their education level was limited to elementary. There was only one patient who completed a college degree. Their income was rather limited. They were overweight and had dyslipidemia in the majority of the cases. Five to six percent were diabetics.

Their initial blood pressure was moderately elevated and all were already taking antihypertensive medicines, usually three or more.

\begin{tabular}{|c|c|c|}
\hline & $\begin{array}{c}\text { Pedometer Group } \\
(n=21)\end{array}$ & $\begin{array}{c}\text { Control Group } \\
(n=21)\end{array}$ \\
\hline Age (years) & $62.9(9.4)$ & $58.5(10.3)$ \\
\hline Female gender $\mathrm{n}(\%)$ & $16(76.2)$ & $14(66.7)$ \\
\hline \multicolumn{3}{|l|}{ Race } \\
\hline White & $2(9.5)$ & $2(9.5)$ \\
\hline Mulatto & $7(33.3)$ & $9(42.9)$ \\
\hline Black & $12(57.1)$ & $10(47.6)$ \\
\hline \multicolumn{3}{|l|}{ Education $n(\%)(*)$} \\
\hline Elementary incomplete & $7(33.3)$ & $8(38.1)$ \\
\hline Elementary complete & $6(28.6)$ & $6(28.6)$ \\
\hline High school & $3(33.3)$ & $7(33.3)$ \\
\hline \multicolumn{3}{|c|}{ Income $-\mathrm{n}=$ multiple of the minimal salary $(\%)$} \\
\hline (1 minimum salary) & $4(19.0)$ & $4(19.0)$ \\
\hline (1-3 minimum wages) & $14(66.7)$ & $14(66.7)$ \\
\hline (3-6 minimum wages) & $3(14.3)$ & $3(14.3)$ \\
\hline Height(m) & $1.6(0.09)$ & $1.6(1.09)$ \\
\hline Weight $(\mathrm{Kg})$ & $74.2(12.4)$ & $80.8(17.0)$ \\
\hline $\mathrm{BMI}\left(\mathrm{Kg} / \mathrm{m}^{2}\right)$ & $30.1(4.0)$ & $32.2(5.1)$ \\
\hline Abdominal circumference $(\mathrm{cm})$ & $99.7(10.9)$ & $101.5(12.7)$ \\
\hline $\operatorname{DLPn}(\%)$ & $14(66.7)$ & $13(61.9)$ \\
\hline $\operatorname{DMn}(\%)$ & $6(28.6)$ & $5(23.8)$ \\
\hline PAS (mmHg) & $146.2(14.6)$ & $153.1(13.0)$ \\
\hline $\mathrm{PAD}(\mathrm{mmHg})$ & $84.0(10.1)$ & $89.1(10.5)$ \\
\hline HR (bpm) & $67.9(7.6)$ & $73.8(12.0)$ \\
\hline
\end{tabular}

* 1 patient in the Pedometer Group had a college degree education. 
The primary endpoint was the number of steps at the end of 12 weeks (Table 4). No difference was shown in the number of steps between Pedometer and Control Groups at the end of 12 weeks.

The secondary endpoints are shown in Table 5. The number of aerobic steps did not change from week 1 to week 12 within the Group and also between Groups. The same was observed with distance, heart rate, and weight. Blood pressure, systolic and diastolic, fell significantly in each Group, but there was no difference between Groups neither in week 1 nor at week 12 . The number of medicines was slightly greater in the Control Group and remained so till week 12. In both Groups, there was a slight increase in the dosage of the individual medicine, which was responsible for the progressive control of the blood pressure.

\section{Discussion}

This was a prospective, randomized study evaluating the possible role of a pedometer use as an additional stimulus to enhance the practice of exercise among patients with difficult-to-control hypertension. The decision to blind the visual display of the pedometer in the first week of utilization before randomization had the intention of avoiding bias.

The use of the pedometer did not increase the number of steps despite the careful observation of the study protocol at the end of a 12-week evaluation.

Table 4. Follow-up of steps/day number at week 1 and week 12.

\begin{tabular}{|c|c|c|c|}
\hline & $\begin{array}{l}\text { Pedometer Group } \\
\qquad(n=21)\end{array}$ & $\begin{array}{l}\text { Control Group } \\
(\mathbf{n}=21)\end{array}$ & $\mathbf{p}$ \\
\hline \multicolumn{4}{|l|}{ Week 1} \\
\hline$n$ of steps mean $( \pm \mathrm{SE})$ & $5,249.1(549.5)$ & $6,191.7(667.3)$ & 0.28 \\
\hline \multicolumn{4}{|l|}{ Week 12} \\
\hline $\mathrm{n}$ of steps mean $( \pm \mathrm{SE})$ & $5,913.0(730.6)$ & $6,097.6(547.0)$ & 0.84 \\
\hline $\mathrm{p}$ & 0.46 & 0.91 & \\
\hline
\end{tabular}

Table 5. Secondary endpoints.

\begin{tabular}{|c|c|c|c|c|c|c|c|c|}
\hline \multirow{2}{*}{$\begin{array}{l}\text { Variable/Mean } \\
\quad( \pm \text { SE })\end{array}$} & \multicolumn{2}{|c|}{ Control G } & \multicolumn{2}{|c|}{ Pedometer G } & \multirow{2}{*}{$\begin{array}{c}\mathrm{p} \\
\text { PW1 vs } \\
\text { CW1 }\end{array}$} & \multirow{2}{*}{$\begin{array}{c}\text { p } \\
\text { CW1 vs } \\
\text { CW12 }\end{array}$} & \multirow{2}{*}{$\begin{array}{c}\text { p } \\
\text { PW1 vs } \\
\text { PW12 }\end{array}$} & \multirow{2}{*}{$\begin{array}{c}\text { p } \\
\text { PW vs } \\
\text { CW12 }\end{array}$} \\
\hline & $\begin{array}{c}\text { Week } \\
1\end{array}$ & $\begin{array}{c}\text { Week } \\
12\end{array}$ & $\begin{array}{c}\text { Week } \\
1\end{array}$ & $\begin{array}{c}\text { Week } \\
12\end{array}$ & & & & \\
\hline \multicolumn{9}{|l|}{ Aerobic steps } \\
\hline $\mathrm{n}$ of steps & $\begin{array}{l}13,57.8 \\
(768.8)\end{array}$ & $\begin{array}{l}21,77.9 \\
(928.0)\end{array}$ & $\begin{array}{c}810.0 \\
(422.0)\end{array}$ & $\begin{array}{c}1,815.4 \\
(1,147.0)\end{array}$ & 0.52 & 0.59 & 0.32 & 0.80 \\
\hline Distance $(\mathrm{km})$ & $\begin{array}{c}3.1 \\
(0.5)\end{array}$ & $\begin{array}{c}4.2 \\
(1.0)\end{array}$ & $\begin{array}{c}2.8 \\
(0.4)\end{array}$ & $\begin{array}{c}2.6 \\
(1.0)\end{array}$ & 0.69 & 0.67 & 0.33 & 0.26 \\
\hline $\mathrm{SBP}(\mathrm{mmHg})$ & $\begin{array}{l}146.2 \\
(3.2)\end{array}$ & $\begin{array}{l}137.8 \\
(3.5)\end{array}$ & $\begin{array}{l}153.1 \\
(2.8)\end{array}$ & $\begin{array}{l}135.7 \\
(3.2)\end{array}$ & 0.11 & 0.08 & 0.002 & 0.66 \\
\hline $\mathrm{DBP}(\mathrm{mmHg})$ & $\begin{array}{l}84.0 \\
(2.2)\end{array}$ & $\begin{array}{l}77.1 \\
(2.4)\end{array}$ & $\begin{array}{l}89.1 \\
(2.3)\end{array}$ & $\begin{array}{l}79.6 \\
(2.6)\end{array}$ & 0.11 & 0.04 & 0.009 & 0.49 \\
\hline $\mathrm{HR}$ (bpm) & $\begin{array}{l}67.9 \\
(1.6)\end{array}$ & $\begin{array}{l}71.4 \\
(2.9)\end{array}$ & $\begin{array}{l}73.8 \\
(2.6)\end{array}$ & $\begin{array}{l}75.6 \\
(2.9)\end{array}$ & 0.06 & 0.30 & 0.64 & 0.28 \\
\hline Weight (Kg) & $\begin{array}{l}74.1 \\
(2.7)\end{array}$ & $\begin{array}{l}74.1 \\
(2.7)\end{array}$ & $\begin{array}{l}81.1 \\
(3.7)\end{array}$ & $\begin{array}{l}81.0 \\
(4.6)\end{array}$ & 0.13 & 1.0 & 0.99 & 0.13 \\
\hline N Medicines & $\begin{array}{c}3.4 \\
(0.15)\end{array}$ & $\begin{array}{c}3.5 \\
(0.18)\end{array}$ & $\begin{array}{c}2.9 \\
(0.18)\end{array}$ & $\begin{array}{c}3.0 \\
(0.15)\end{array}$ & 0.04 & 0.67 & 0.67 & 0.03 \\
\hline
\end{tabular}

PW - pedometer week; CW - control week; vs - versus; C - control; G - group. 
Neither was their changes in the aerobic steps nor in the distance achieved.

The blood pressure fell in both Groups as a result of the dosage of medicines in the majority of cases. It should be observed that the Control Group started and ended the study with a slightly greater number of antihypertensive medicines, but the blood pressure was similar between Groups at the end of the study.

The reasons for the lack of efficacy of the use of the pedometer as a stimulus to increase the number of daily steps are manifold and worth considering. The study design for both Groups was to instruct the study population to pursue good clinical habits including the stimulus for the exercise, since it has been demonstrated in multiprofessional education programs for hypertensive patients, which appears to be very effective in promoting a better blood pressure control.

Furthermore, we have chosen a population with characteristics that favor the daily walking process: they were mostly low-income, uneducated, and living in the peripheral neighborhoods. So, they naturally depend on daily walking for the accomplishment of their endeavors.

In other studies, the number of steps in the baseline condition was much less than in our study. ${ }^{14}$

Apparently, in healthy populations, as primary prevention, the use of a pedometer could be a valuable tool. ${ }^{15,16}$

\section{Conclusion}

In our study of low-income, physically active patients, attending a specialized hypertensive clinic, where there is a multiprofessional education regarding good health care, including a general stimulus to exercise, the use of a pedometer did not enhance the physical activity of the patients included in the study.

\section{References}

1. Alevizos A, Lentzas J, Kokkoris S, Mariolis A, Korantzopoulos P. Physical activity and stroke risk. Int J Clin Pract. 2005;59:922-30.

2. Gregg EW, Gerzoff RB, Caspersen CJ, Williamson DF, Narayan KM. Relationship of walking to mortality among US adults with diabetes. Arch Intern Med. 2003;163:1440-7.
3. Fanous AM, Kier KL, Rush MJ, Terrell S. Impact of a 12-week, pharmacist-directed walking program in an established employee preventive care clinic. Am J Health Syst Pharm. 2014;71:1219-25.

4. Okura T, Enomoto D, Miyoshi KI, Nagao T, Kukida M, Tanino A, et al. The importance of walking for control of blood pressure: proof using a Telemedicine system. Telemed J E Health. 2016;22:1019-23.

5. Yu Y, Lv Y, Yao B, Duan L, Zhang X, Xie L, Chang C. A novel prescription pedometer-assisted walking intervention and weight management for Chinese occupational population. PLoS One. 2018;13:e0190848.

6. Cooke AB, Pace R, Chan D, Rosenberg E, Dasgupta K, Daskalopoulou SS. A qualitative evaluation of a physiciandelivered pedometer-based step count prescription strategy with insight from participants and treating physicians. Diabetes Res Clin Pract. 2018;139:314-322.

7. Nowicki M, Murlikiewicz K, Jagodzinska M. Pedometers as a means to increase spontaneous physical activity in chronic hemodialysis patients. J Nephrol. 2010;23:297-305.

8. Stathokostas L, Speechley M, Little RM, Doerksen S, Copeland J, Paterson DH. Long-term evaluation of the "Get Fit for Active Living” Program. Can J Aging. 2017;36:67-80.

9. LorenzEC,Amer H, Dean PG, Stegall MD, Cosio FG, Cheville AL. Adherence to a pedometer-based physical activity intervention following kidney transplant and impact on metabolic parameters. Clin Transplant. 2015;29:560-8.

10. Diretriz Brasileira de Hipertensao Arterial: Malachias MVB, Souza WKSB, Plavnik FL, Rodrigues CIS, Brandão AA, Neves MFT, et al. $7^{\mathrm{a}}$ Diretriz Brasileira de Hipertensão Arterial. Arq Bras Cardiol. 2016;107(3Supl.3):1-83.

11. Jenkins DJA, Boucher BA, Ashbury FD, et al. Effect of current dietary recommendations on weight loss and cardiovascular risk factors. JAmCollCardiol. 2017;69:1103-12.

12. Juraschek SP, Woodward M, Sacks FM, Carey VJ, Miller ER, 3rd, Appel LJ. Time course of change in blood pressure from sodium reduction and the DASH diet. Hypertension. 2017;70:923-9.

13. Tudor-Locke C, Craig CL, Aoyagi Y, Bell RC, Croteau KA, De Bourdeaudhuij I, et al. How many steps/day are enough? For older adults and special populations. Int $\mathrm{J}$ Behav Nutr Phys Act. 2011;8:80.

14. Dasgupta K, Joseph L, Pilote L, Strachan I, Sigal RJ, Chan C. Daily steps are low year-round and dip lower in fall/winter: findings from a longitudinal diabetes cohort. Cardiovasc Diabetol. 2010;9:81.

15. Leung AY, Cheung MK, Tse MA, Shum WC, Lancaster BJ, Lam CL. Walking in the high-rise city: a health enhancement and pedometer-determined ambulatory (HEPA) program in Hong Kong. Clin Interv Aging. 2014;9:1343-52.

16. Paula TP, Viana LV, Neto AT, Leitao CB, Gross JL, Azevedo MJ. Effects of the DASH diet and walking on blood pressure in patients with type 2 diabetes and uncontrolled hypertension: a randomized controlled trial. J Clin Hypertens (Greenwich). 2015;17:895-901. 